\title{
Fermentation of the Straw Material Paja Brava by the Yeast Pichia stipitis in a Simultaneous Saccharification and Fermentation Process
}

\author{
Cristhian Carrasco ${ }^{1,2}$, Henrique Baudel ${ }^{3}$, Christian Roslander ${ }^{1}$, Mats Galbe ${ }^{1}$, Gunnar Lidén ${ }^{1 *}$ \\ ${ }^{1}$ Department of Chemical Engineering, Lund University, Lund, Sweden \\ ${ }^{2}$ Instituto de Investigación y Desarrollo de Procesos Químicos, Ingeniería Química, \\ Universidad Mayor de San Andrés, La Paz, Bolivia \\ ${ }^{3}$ Department of Chemical Engineering, Federal University of Pernambuco, Recife, Brazil \\ Email: "gunnar.liden@chemeng.lth.se
}

Received March 11, 2013; revised April 15, 2013; accepted May 10, 2013

Copyright (C) 2013 Cristhian Carrasco et al. This is an open access article distributed under the Creative Commons Attribution License, which permits unrestricted use, distribution, and reproduction in any medium, provided the original work is properly cited.

\begin{abstract}
Paja Brava is a native South American grass with a high carbohydrate content. In the current work, the potential of using this feedstock for ethanol production using a simultaneous saccharification and fermentation (SSF) process with the xylose-fermenting yeast Pichia stipitis (Scheffersomyces stipitis) CBS6054 was investigated. The straw material was subjected to $\mathrm{SO}_{2}$ catalyzed steam pretreatment at $200^{\circ} \mathrm{C}$ and $5 \mathrm{~min}$ residence time, which resulted in a solubilization of pentose sugars (mainly xylose) of $64 \%$ with only minor amounts of degradation products. The obtained material, including the pretreatment liquid, was subsequently hydrolyzed and fermented in an SSF process at microaerobic conditions using either a batch or a fed-batch process at a total water-insoluble solids loading of $10 \%$. Overall yields of ethanol based on all available sugars of $0.24 \mathrm{~g} / \mathrm{g}$ and $0.27 \mathrm{~g} / \mathrm{g}$ were obtained for batch and fed-batch mode of operation, respectively. The higher yield in the fed-batch process coincided with a higher degree of conversion of the sugars in the liquid medium, in particular of arabinose, for which the conversion was doubled (from $48 \%$ to $97 \%$ ).
\end{abstract}

Keywords: Ethanol; Lignocellulose; Fermentation; Xylose

\section{Introduction}

Paja Brava, a Gramineae material, is the most common native grass species on the Bolivian Altiplano and is also widely distributed in South America in general [1]. In this straw, D-xylose is the most predominant hemicellulosic sugar, constituting up to $25 \%$ of the total dry weight, which is similar to straw materials such as wheat straw or sugarcane bagasse $[2,3]$. Production of ethanol from lignocellulose requires cost-effective and environmentally sustainable processes [4]. Principal options for ethanol production from lignocellulosics by the biological route include enzymatic hydrolysis followed by fermentationSeparate Hydrolysis and Fermentation, SHF-or Simultaneous Saccharification and Fermentation, SSF. The latter may include conversion of both conversion of $\mathrm{C} 5$ and C6 sugars, in which case the term simultaneous saccharification and co-fermentation, SSCF, is used [5]. Significant advances have been made on the bioconversion of

${ }^{*}$ Corresponding author.
D-xylose into ethanol by genetic engineering of the yeast Saccharomyces cerevisiae to convert also xylose (e.g. [6]), which has been successfully applied for the conversion of Paja Brava in SSF [7]. Other options include fermentation by engineered Escherichia coli [8] or Zymomonas mobilis [9]. There are also naturally pentose fermenting yeasts, most notably Pichia stipitis and Candida shehatae, which offer a direct route [10] albeit requiring microaerobic conditions [11]. P. stipitis is likely the most interesting of the natural xylose fermenting yeasts, since it is able to ferment a wider range of sugars and produces relatively little xylitol [12]. In previous studies hydrolyzate fermentation by $P$. stipitis, inhibition effects by acid-hydrolysis derived products, e.g. furans, aliphatic acids and phenolic derivatives, were observed. The fermentation processes could be improved by a partial or a complete removal of these toxic compounds (detoxification), or through the adaptation of yeast by preculturing on hydrolysate as medium [13]. Fed-batch SSCF is another attractive process option. With this approach, slurry 
is gradually fed into the reactor which provides a chance for adaptation as well as in-situ detoxification, i.e. a bioconversion of primarily inhibiting aldehyde compounds [14]. An additional advantage of the fed-batch process is that higher solids loading can be applied than in batch mode, since the mixing problems due to a too high viscosity can be reduced [5]. A high solids loading will contribute to the reduction of water use for ethanol production and improve the process economy [15].

The objective of the present study was to assess the potential of the natural xylose-fermenting yeast $P$. stipitis (CBS6054) to ferment pretreated Paja Brava using the process concept simultaneous saccharification and cofermentation (SSCF). In addition, batch and fed-batch operation in the SSCF were compared.

\section{Methods}

\subsection{Raw Material}

The Paja Brava (the brave straw) used in this study was obtained from the Bolivian Altiplano, $\left(17^{\circ} \mathrm{S}\right.$ Latitude, $67^{\circ} \mathrm{W}$ Longitude). The whole plant above ground was used. Dry material was prepared and analyzed in the same way as described previously [7]. Its composition on an original dry weight (DW) straw basis was glucan, $34.4 \%$; xylan, $25.2 \%$; arabinan, $3.0 \%$; galactan, $0.8 \%$; Klason lignin, 21.2\%; acid soluble lignin, 3.5\%; acetyl, $1.2 \%$; extractives, $2.4 \%$; and ash, $6.1 \%$.

\section{2. $\mathrm{SO}_{2}$-Catalysed Steam Pretreatment}

Several batches (300 g DW, 64\% moisture content) of Paja Brava were pretreated at $200^{\circ} \mathrm{C}$ for $5 \mathrm{~min}$ using $2.5 \% \mathrm{SO}_{2}$ (percentage DW basis) in a pretreatment unit as described by Palmqvist et al. [16]. These conditions have previously been determined to be optimal for steam pretreatment of Paja Brava, as described elsewhere [7]. The pretreated straw was collected and subsequently separated in two fractions (pulp and hydrolysate).

\subsection{Yeaststrain and Medium}

The xylose-fermenting yeast Pichia stipitis CBS6054 obtained from Centraalbureauvoor Schimmelcultures, Delft, The Netherlands was used throughout the work. The culture was routinely maintained on agar plates made from yeast extract $10 \mathrm{~g} / \mathrm{L}$ (Merck, Darmstadt, Germany), peptone from soy $20 \mathrm{~g} / \mathrm{L}$ (Merck, Darmstadt, Germany), agar agar 20 g/L (Merck, Darmstadt, Germany) and D-glucose $20 \mathrm{~g} / \mathrm{L}$ (Sigma, Germany) as additional carbon resource.

\subsection{Yeast Production}

Culture media $(200 \mathrm{~mL})$ were prepared by adding mineral and salt solutions at the concentrations reported by Taherzadeh et al. [17] with the exception of the D-glu- cose concentration (Sigma, Germany), which in the current study was $16.5 \mathrm{~g} / \mathrm{L}$. Synthetic medium and glucose were adjusted to $\mathrm{pH} 5.5(\mathrm{NaOH} 2.0 \mathrm{M})$ and autoclaved separately for $20 \mathrm{~min}$ at $121^{\circ} \mathrm{C}$. After cooling to about $25^{\circ} \mathrm{C}$, vitamin solution was added under aseptic conditions. The precultures were aerobically conducted in cotton-plugged unbaffled conical flasks $(500 \mathrm{~mL})$ using a thermostatic bath shaker (GYROMAX TM 929, Amerex instruments, Inc., Lafayette, CA, USA) at $160 \mathrm{rpm}$ and $30^{\circ} \mathrm{C}$ for $24 \mathrm{~h}$. In the fermentation of hemicellulose hydrolyzates, culture broth from the E-flasks was centrifuged in $50 \mathrm{~mL}$ centrifuge tubes at $1800 \times \mathrm{g}$ for $10 \mathrm{~min}-$ utes. Thereafter, the cell pellet was washed with sterile sodium chloride, $0.9 \%(\mathrm{w} / \mathrm{v})$, and added in each hydrolysate medium flask to reach the desired cell concentration, which in the current study was $5 \mathrm{~g} / \mathrm{L}$ DW. Cell growth was measured off-line by the optical density at $610 \mathrm{~nm}$. SSCF experiments were preceded by a twophase yeast cultivation (batch and fed-batch) to produce the yeast needed according to Rudolf et al. [18]. First, a batch cultivation of $P$. stipitis was made in a $2.5 \mathrm{~L}$ reactor (Biostat A plus Sartorious BBI systems, Melsungen, Germany) with a defined growth medium containing (per liter of solution): D-glucose, $21 \mathrm{~g} ;\left(\mathrm{NH}_{4}\right)_{2} \mathrm{SO}_{4}, 26 \mathrm{~g}$; $\mathrm{KH}_{2} \mathrm{PO}_{4}, 12 \mathrm{~g} ; \mathrm{MgSO}_{4} \cdot 7 \mathrm{H}_{2} \mathrm{O}, 0.75 \mathrm{~g}$; trace metal solution, $10 \mathrm{~mL}$; and vitamin solution, $1 \mathrm{~mL}$; the composition of the last two solutions as specified in Taherzadeh et al. [17]. The batch cultivation was started by injection of 25 $\mathrm{mL}$ of inoculum. A total working volume of $0.7 \mathrm{~L}$, including inoculum and medium, was used. The batch cultivations were made at a stirrer rate of $900 \mathrm{rpm}$, a temperature of $30^{\circ} \mathrm{C}$, a pH of 5.0 (controlled by automatic addition of $3.0 \mathrm{M} \mathrm{NaOH}$ ), and using an aeration rate of $1.0 \mathrm{~L} / \mathrm{min}$ (controlled by a mass-flow meter Bronckhorst Hi-Tech, Ruurlo, The Netherlands). The fed-batch cultivation started after depletion of the ethanol produced in the batch cultivation. A pentose-rich hydrolysate (Table 1), obtained from the steam pretreatment was used. The medium was supplemented with $35 \mathrm{~g} / \mathrm{L}$ of D-glucose. The total substrate volume was $1.1 \mathrm{~L}$. The initial feed rate was $0.04 \mathrm{~L} / \mathrm{h}$ and this was linearly increased to 0.10 $\mathrm{L} / \mathrm{h}$ in $16 \mathrm{~h}$. The fed-batch conditions were the same as those in the batch cultivation with the exception of the aeration rate which was increased to $1.4 \mathrm{~L} / \mathrm{min}$. The yeast produced was harvested aseptically by centrifugation $(3000 \times \mathrm{g}$ for $7 \mathrm{~min})$ at $4^{\circ} \mathrm{C}$, washed and then resuspended in approximately $250 \mathrm{~mL} \mathrm{NaCl}(0.9 \%)$ to give a cell concentration of $5 \mathrm{~g} / \mathrm{L}$ in SSF experiments. Chemicals were obtained from Sigma-Aldrich Co, Riedel-de Haën, and Merck.

\subsection{Fermentation}

\subsubsection{Hemicellulose Hydrolysate}

$35 \mathrm{~mL}$ sterile flasks (working volume $26.4 \mathrm{~mL}$ ) equipped 
Table 1. Composition of hemicellulose hydrolysate and cellulose fibre fraction from Paja Brava.

\begin{tabular}{cc}
\hline Hydrolysate & $(\mathrm{g} / \mathrm{L})$ \\
\hline Cellobiose & $3.1 \pm 0.05$ \\
Glucose & $3.9 \pm 0.08$ \\
Xylose & $40.6 \pm 1.4$ \\
Arabinose & $6.2 \pm 0.01$ \\
Acetic acid & $2.9 \pm 0.13$ \\
Levulinic acid & $0.34 \pm 0.01$ \\
Formic acid & $0.40 \pm 0.01$ \\
Furfural & $1.5 \pm 0.03$ \\
HMF & $0.5 \pm 0.02$ \\
\hline Pretreated pulp & $(\mathrm{g} / 100 \mathrm{~g} \mathrm{DM})$ \\
\hline Glucan & $63.6 \pm 0.9$ \\
Xylan & $2.4 \pm 0.03$ \\
Arabinan & $0.80 \pm 0.1$ \\
Lignin & $30.2 \pm 0.9$ \\
\hline
\end{tabular}

${ }^{*}$ The material was pretreated at $200^{\circ} \mathrm{C}$ with a holding time of 5 min using $2.5 \% \mathrm{SO}_{2}$; Presented values are mean values of duplicate experiments. Standard deviations are given as \pm .

with cotton stoppers through which a syringe for sample withdrawal were used for the semi-aerobic fermentations at $220 \mathrm{rpm}$ at $30^{\circ} \mathrm{C}$ in an orbital shaker (Forma scientific Inc., Marietta, USA). In anaerobic experiments, a sterile $300 \mathrm{~mL}$ flask (working volume $105.6 \mathrm{~mL}$ ), equipped with a loop-trap according to Carrasco et al. [3], was placed in a rotary shaker (GYROMAX TM 929, Amerex instruments, Inc., Lafayette, CA, USA) at $170 \mathrm{rpm}$ at $30^{\circ} \mathrm{C}$. The fermentation broth contained the following: $90.0 \mathrm{~mL}$ of hydrolysate; $11.6 \mathrm{~mL}$ of nutrient solution and $4.0 \mathrm{~mL}$ of inoculum. Nutrient solution, mineral salts and trace elements, were prepared according to Taherzadeh et al. [19]. The composition of the hemicellulose hydrolysate of Paja Brava is shown in Table 1. A control anaerobic fermentation, simulating the Paja Brava hemicellulose hydrolysate, was also performed. The synthetic medium contained (g/L), D-xylose, 40.3 (Merck, Darmstadt, Germany); D-glucose, 3.9 (Sigma, Germany); L-arabinose, 6.2 (Sigma, Germany); and the same supplementation of nutrients as described previously. All liquid media were $\mathrm{pH}$-adjusted to 5.5 with $\mathrm{NaOH}(2.0 \mathrm{M})$. The hemicellulose-fraction experiments were started by inoculation of yeast (to reach $5 \mathrm{~g} \mathrm{DW} / \mathrm{L}$ ). Aliquots of $1 \mathrm{~mL}$ were withdrawn periodically to determine cell mass and stored at $-18^{\circ} \mathrm{C}$ for later HPLC analyses. Samples of micro-aerobic and anaerobic fermentations were taken after $0,2,8,20,44,68$ and 92 and $0,2,4,6,8,24,48,72$ and $96 \mathrm{~h}$, respectively. All experiments were carried out in duplicates.

\subsubsection{Simultaneous Saccharification and Co-Fermentation (SSCF)}

Batch and fed-batch SSCF experiments, with a waterinsoluble solids (WIS) content of pretreated Paja Brava slurry of $10 \%$ were carried out in $2.5 \mathrm{~L}$ lab-scale biore- actors Biostat A, (B. Braun Biotech International), and Biostat A plus Sartorious BBI systems (Melsungen, Germany). The WIS content was determined according to Posey et al. [20]. A working weight of $1.4 \mathrm{~kg}$ (approx $1.4 \mathrm{~L}$ ) was used. The preparation of slurry by addition of nutrients, enzymes and yeast, for both batch and fedbatch mode, was made according to Carrasco et al. [7]. In the fed-batch experiments, a total of six portions of slurry were added every second hour to reach the intended final WIS content. The SSCF fermentations were performed at a stirrer rate of $500 \mathrm{rpm}$ a temperature of $35^{\circ} \mathrm{C}$ and a pH-value of 6.0 (controlled by automatic addition of $0.3 \mathrm{M} \mathrm{NH}_{3}$ ). The temperature and $\mathrm{pH}$ were selected according to Rudolf et al. [18]. Two aeration rates, 20 and $40 \mathrm{~mL} / \mathrm{min}$ (controlled by a mass-flow meter Bronckhorst Hi-Tech, Ruurlo, The Netherlands) were tested. Samples for metabolite analyses were taken after $0,2,4,6,8,24,28,32,48,72$ and $96 \mathrm{~h}$, and were immediately centrifuged and stored at $-18^{\circ} \mathrm{C}$ until analyzed. All experiments were carried out in duplicates.

\subsubsection{Analyses}

1) Biomass

Dry weight was determined turbidometrically at 610 $\mathrm{nm}$ (OD610) after the samples were diluted 1:10 in MilliQ-water to obtain absorbance values less than 0.5 in the spectrophotometer (SECOMAN CE, France). Cell dry weight was also determined by duplicate $10 \mathrm{~mL}$ samples, which were centrifuged at $1000 \times \mathrm{g}$ for $3 \mathrm{~min}$. The supernatants were discarded and cell pellets were washed three times with distilled water and dried for $24 \mathrm{~h}$ at $105^{\circ} \mathrm{C}$ and subsequently weighed.

2) Metabolite Analysis

Prior to analysis by HPLC (Waters 1515, Milford, MA, USA), oligomeric and monomeric sugars and by-products (as furans and aliphatic acids) obtained as watersoluble solids (WSS) were analyzed according to the NREL procedure described in Sluiter et al. [21]. All hydrolysate samples were centrifuged at $16000 \times \mathrm{g}$ for 5 min and filtered through $0.20 \mu \mathrm{m}$ sterile filters. The pretreated pulp composition of Paja Brava was analyzed according to the NREL standard assay [22]. Cellobiose, glucose, galactose, xylose and arabinose, from liquid and solid fractions, were analyzed on an Aminex HPX-87P column (Bio-Rad laboratories, Hercules, CA, USA) at $85^{\circ} \mathrm{C}$. MilliQ-water was used as eluent at a flow rate of $0.6 \mathrm{~mL} / \mathrm{min}$. Ethanol, xylitol, glycerol, acetic acid, levulinic acid, formic acid, 5-hydroxymethyl furfural (HMF) and furfural were determined using an Aminex HPX-87H column (Bio-Rad laboratories, Hercules, CA, USA) at $60^{\circ} \mathrm{C}$ with $0.6 \mathrm{~mL} / \mathrm{min}$ eluent of $5 \mathrm{mM} \mathrm{H} 2 \mathrm{SO} 4$. All metabolites were quantified using a refractive index detector (Waters 2410, Waters, Milford, MA, USA) with the exception of acetic acid, HMF and furfural, which were 
quantified using an ultraviolet (UV) dual absorbance detector Waters 2487 (Milford, MA, USA) at $210 \mathrm{~nm}$.

\subsection{Calculations of Yields}

Yield calculations $\left(\mathrm{g} \cdot \mathrm{g}^{-1}\right)$ were based on the total sugar content, hexoses and pentoses, in the pretreated straw and the pretreatment liquid. The amount of ethanol produced in the SSCF was divided by the available amounts of glucose, xylose, and arabinose - including oligomers present in the slurry at the beginning of the experiment.

\section{Results and Discussion}

\subsection{Fermentation of Pretreatment Liquid}

During pretreatment a number of inhibitors can potentially be formed, most of which are found in the liquid fraction. For this reason, the fermentability of the nondetoxified liquid fraction from the pretreatment (i.e. the hemicellulose hydrolysates) of Paja Brava was first evaluated using the xylose-fermenting yeast $P$. stipitis CBS6054. It is well-know that microaerobic conditions improve xylose uptake by P. stipitis [11]. For this reason both anaerobic experiments and semi-aerobic experiments were made in the initial evaluation of inhibiting properties. In previous studies, $\mathrm{SO}_{2}$-steam pretreatment has resulted in a relatively high concentration of hemicellulose sugars in the liquid fraction for different feedstock $[3,23]$. Xylose was found to be the completely dominant sugar in the liquid fraction after steam pretreatment (about $40 \mathrm{~g} / \mathrm{L}$ ), followed by arabinose (about 6 $\mathrm{g} / \mathrm{L}$ ), whereas only relatively low amounts of glucose and cellobiose were found in the liquid fraction (cf. Table 1). This agrees well with the fact that mainly the hemicellulose fraction is hydrolyzed during the steam pretreatment. Other compounds found at significant levels included acetic acid, a few grams per liter-formed from deacetylation of hemicellulose - as well as some furfuralformed as breakdown product of pentoses. In the anaerobic fermentation tests, the extent of inhibition was tested by comparing to fermentation of a synthetic medium with the same sugar concentration as the hydrolysate. Furthermore, tests were made in the semi-aerobic fermentations in which additional glucose was added, to investigate potential beneficial effects of presence of glucose. The simultaneous fermentation of (low amounts of) glucose has previously been shown beneficial for xylose fermentation in engineered xylose-fermenting $S$. cerevisiae strains [24].

The conversion of the hydrolysate sugars when fermenting the pretreatment liquid alone was low under both anaerobic and semiaerobic conditions (Table 2). Only a minor fraction $(<10 \%)$ of the sugars were converted anaerobically in the pretreatment liquid, in contrast to the case of a synthetic medium containing the same amount of sugars, in which all the glucose and half the xylose was consumed although at a low rate. The low rate of anaerobic conversion agrees with previous studies $[11,25]$. The difference between the synthetic medium and the pretreatment liquid indicate inhibitory effects on the $P$. stipitis fermentation. However, under semi-aerobic conditions, it was possible to obtain a reasonable conversion of glucose, especially for the case when glucose (20 $\mathrm{g} / \mathrm{L}$ ) was added to the medium. An ethanol yield of 0.13 $\mathrm{g} / \mathrm{g}$ was obtained in this case showing that the inhibition per se was not complete, but rather that the xylose conversion was very low. Glucose was the preferred carbon source and was completely assimilated before xylose uptake started.

\subsection{Simultaneous Saccharification and Fermentation}

In SSF, the glucose is gradually released to the medium through enzymatic hydrolysis of the cellulose fraction, in contrast to the experiments made with glucose addition to the pretreatment liquid described above. One may therefore expect further benefits from the SSF than the simple addition experiments, since glucose is released during a longer time period. The oxygen transfer rate (OTR) is a critical environmental factor in xylose fermentation by $P$. stipitis [11]. In this study, an oxygenation rate of $8 \mathrm{mmol}$ oxygen/L.h was used, which is the same oxygenation rate as was used by Rudolf et al. [18] in their study on conversion of sugarcane bagasse. Increase of the aeration up to $16 \mathrm{mmol}$ oxygen/L.h was also tested, but in that aeration rate was shown to be too high and virtually no ethanol was formed.

Both batch and fed-batch SSF fermentations were carried out using fully undetoxified hydrolysate slurry (Figures 1 and 2). A WIS loading of pretreated material of $10 \%$ was used in the batch fermentations. The fed-batch fermentations started with $6 \%$ WIS and material was then gradually added to give a total added WIS loading of $10 \%$ as in the batch case. It was quite clear that the SSF fermentation (Table 3) was strongly improved in comparison to the fermentation of pretreatment liquid only (cf. Table 2), giving a much larger conversion of the pentose sugars in the liquid phase. Final ethanol titers around $20 \mathrm{~g} / \mathrm{L}$ were obtained and xylose conversions were above $80 \%$. This can be compared to results reported by Rudolf et al. [18] for sugar cane bagasse, in which a xylose conversion around $90 \%$ was obtained at a WIS content of $7.5 \%$ with P. stipitis CBS6054 in SSF, i.e. even higher than found in the present study. However, the WIS loading in this study was higher than that of Rudolf et al. [18], and any increase in the WIS loading in SSF/SSCF normally results in a decrease in xylose conversion-mostly due to higher amounts of inhibitors present in the slurry [2,7]. Although the yields obtained 
Table 2. Sugar conversions and yields obtained in shake flask fermentations of hemicellulose hydrolysates by $P$. stipitis.

\begin{tabular}{|c|c|c|c|c|c|c|c|c|c|c|}
\hline $\begin{array}{l}\text { Medium/ } \\
\text { Condition }\end{array}$ & $\begin{array}{c}\text { Glu Conv. }^{\mathrm{b}} \\
(\%)\end{array}$ & $\begin{array}{c}\text { Xyl Conv. } \\
(\%)\end{array}$ & $\begin{array}{c}\text { Ara Conv. } \\
(\%)\end{array}$ & $\begin{array}{c}{ }^{\mathrm{b}} \mathrm{Cb} \text { Conv. } \\
(\%)\end{array}$ & $\begin{array}{l}Y_{\text {sxylit }}{ }^{\mathrm{c}} \\
(\mathrm{g} / \mathrm{g})\end{array}$ & $\begin{array}{l}Y_{\text {sglyc }}{ }^{d} \\
(\mathrm{~g} / \mathrm{g})\end{array}$ & $\begin{array}{l}Y_{\mathrm{sx}}{ }^{\mathrm{e}} \\
(\mathrm{g} / \mathrm{g})\end{array}$ & $\begin{array}{c}Y_{\text {se }}^{\mathrm{f}} \\
(\mathrm{g} / \mathrm{g})\end{array}$ & $\begin{array}{c}\text { Ethanol } \\
(\mathrm{g} / \mathrm{L})\end{array}$ & $\begin{array}{c}\mathrm{Q}_{\max 20 \mathrm{~h}^{\mathrm{g}}} \\
(\mathrm{g} / \mathrm{L} \cdot \mathrm{h})\end{array}$ \\
\hline Synthetic/Anaerobic & 100 & 50 & 9 & - & $0.02 \pm 0.01$ & 0.00 & $0.08 \pm 0.01$ & $0.25 \pm 0.01$ & $11.4 \pm 0.1$ & $0.08 \pm 0.10$ \\
\hline Hydrolysate/Anaerobic & 10 & 4 & 7 & 32 & - & 0.00 & $0.17 \pm 0.01$ & $0.01 \pm 0.0$ & $0.3 \pm 0.1$ & 0.0 \\
\hline Hydrolysate/Semiaerobic & 45 & 9 & 24 & 3 & $0.10 \pm 0.0$ & $0.009 \pm 0.00$ & $0.27 \pm 0.03$ & 0.0 & $0.2 \pm 0.02$ & $0.01 \pm 0.0$ \\
\hline $\begin{array}{l}\text { Hydrolysate + glucose } \\
20 \mathrm{~g} / \mathrm{L} / \text { Semiaerobic }\end{array}$ & $100^{\mathrm{a}}$ & 7 & 6 & 5 & $0.22 \pm 0.03$ & $0.015 \pm 0.00$ & $0.22 \pm 0.05$ & $0.13 \pm 0.01$ & $8.2 \pm 0.6$ & $0.4 \pm 0.03$ \\
\hline
\end{tabular}

Presented values are mean values of duplicate experiments. Standard deviations are given as \pm . Arabitol was not measured and the calculations were performed after 20 hours. ${ }^{a}$ Includes glucose supplementation $(20 \mathrm{~g} / \mathrm{L})$; ${ }^{b}$ sugar conversion; ${ }^{c}$ xylitol yield based on consumed xylose; ${ }^{d}$ glycerol yield on total glucose and xylose; 'biomass yield on the total sugars in the material; ${ }^{\mathrm{f}}$ ethanol yield based on the total sugars in the material with the exception of arabinose; ${ }^{\mathrm{g}}$ maximum volumetric productivity after 20 hours. Glucose (Glu); xylose (Xyl); arabinose (Ara); Xylitol (xylit); Glycerol (glyc) and cellobiose (Cb).

Table 3. Measured final concentrations of ethanol, sugar consumptions and by-products as well as calculated yields in simultaneous saccharification and co-fermentation experiments using the xylose-fermenting yeast $P$. stipitis CBS6054.

\begin{tabular}{|c|c|c|c|c|c|c|c|c|c|c|c|}
\hline \multirow{2}{*}{ SSCF } & WIS & Xyl Cons. ${ }^{b}$ & Ara Cons. ${ }^{b}$ & Cb Cons. ${ }^{b}$ & $Y_{\text {sxylt }}{ }^{c}$ & $\mathrm{Y}_{\text {sarabt }}{ }^{\mathrm{d}}$ & $Y_{\text {sglyc }}{ }^{e}$ & $Y_{s e}{ }^{f}$ & $\mathrm{Y}_{\mathrm{se}}^{\mathrm{g}}$ & Ethanol & $\mathrm{Q}_{\max 24 \mathrm{~h}^{\mathrm{h}}}$ \\
\hline & $(\%)$ & $(\%)$ & $(\%)$ & $(\%)$ & $(\mathrm{g} / \mathrm{g})$ & $(\mathrm{g} / \mathrm{g})$ & $(\mathrm{g} / \mathrm{g})$ & $(\mathrm{g} / \mathrm{g})$ & $(\%)$ & $(g / L)$ & $(g / L \cdot h)$ \\
\hline Batch & 10 & 82 & 48 & 64 & $0.14 \pm 0.01$ & $0.63 \pm 0.08$ & $0.04 \pm 0.01$ & $0.24 \pm 0.0$ & 47 & $19.1 \pm 0.5$ & $0.35 \pm 0.03$ \\
\hline Fed-batch ${ }^{\mathrm{a}}$ & $6-10$ & 89 & 97 & 79 & $0.16 \pm 0.02$ & $0.25 \pm 0.02$ & $0.06 \pm 0.01$ & $0.27 \pm 0.01$ & 52 & $22.4 \pm 0.7$ & $0.41 \pm 0.02$ \\
\hline
\end{tabular}

Presented values are mean values of duplicate experiments. Standard deviations are given as \pm . Experiment conditions were carried out at flow-rate $(20 \mathrm{~mL} / \mathrm{h})$

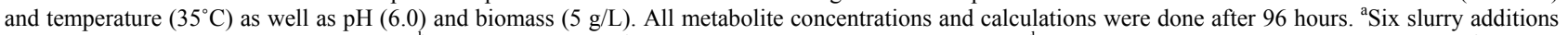
during 12 hours (starting: 6 to 10\% WIS); ${ }^{b}$ sugar consumption; ${ }^{c}$ xylitol yield based on consumed xylose; ${ }^{d}$ arabitol yield based on consumed arabinose; ${ }^{\text {g }}$ glycerol yield on total xylose and glucose; ${ }^{\mathrm{f}}$ ethanol yield based on the total sugars in the material; ${ }^{\mathrm{g}}$ percentage of maximum theoretical ethanol yield; ${ }^{\mathrm{h}}$ maximum volumetric productivity after 24 hours. Xylose (Xyl); arabinose (Ara); and cellobiose (Cb).

from Paja using $P$. stipitis compare well with yields obtained from sugar cane bagasse, it is clearly lower that what has been reported from Paja Brava using a genetically engineered $S$. cerevisiae strain, for which an ethanol yield close to $0.4 \mathrm{~g} / \mathrm{g}$ was obtained [7]. Further improvements in the ethanol yield in the case of $P$. stipitis may be possible by further optimization of the aeration. However, this is not trivial since the rates change over time as a function of hydrolysis rate and cell concentration.

The fed-batch mode of SSF operation gave a somewhat higher overall ethanol yield than the batch case (Table 3). This is explained by the higher conversion of xylose, arabinose and cellobiose. In the batch SSF (Figure 1), the glucose concentration increased for the first 10 hours, reaching $3 \mathrm{~g} / \mathrm{L}$, whereas in the fed-batch case, the glucose concentration stayed below $3 \mathrm{~g} / \mathrm{L}$ and the concentration peaked at $6 \mathrm{~h}$. The initial increase in glucose concentration is caused by a higher initial rate of enzymatic hydrolysis than the rate of glucose consumption. As the hydrolysis proceeds, the rate of hydrolysis falls, resulting in a net decrease of glucose concentration. The glucose concentration in the fed-batch case stayed below that of the batch case throughout the process. Similarly, the xylose concentration decreased more rapidly in the fed-batch case than in the batch case. The yeast $P$. stipitis is able to transport both glucose and xylose (via lowaffinity system) by proton gradient-linked transporters $[26,27]$. The conversion of C5 sugars to ethanol was sig- nificantly improved by SSCF in comparison to the shake flask fermentations. Most likely this is connected to the co-utilization of glucose and the fact that the glucose concentration was lower than in the shake flask studies. According to Panchal et al. [28] the glucose should be well below $2 \%(\mathrm{w} / \mathrm{v}))$, before significant xylose uptake is initiated in the slurry substrate. Also for some Candida species (C. shehatae and C. stearolytica), utilization of xylose requires that the glucose stays below 3\% - 5\% $(\mathrm{w} / \mathrm{v})$ in the medium $[28,29]$.

The xylose conversion was high already in the batch case, and even higher in the fed-batch case (Table 3). This may be connected to the lower glucose concentration, and thereby a more favorable xylose to glucose ratio in the fed-batch case, similar to what has been found for engineered xylose fermenting S. cerevisiae [30]. However, this is not the only factor. The conversion rate of the furaldehydes, furfural and HMF, were lower in the batch than in the fed-batch case (Figure 1). Since furfural is known to be reduced by the xylose reductase of $P$. stipitis [31], a competitive inhibition of xylose reductase by furfural could explain a lower xylose conversion rate in the batch case. The furaldehydes may also affect the enzymatic hydrolysis of the fibers [32].

The pretreatment liquid from Paja Brava contains in addition to xylose, also significant amounts of cellobiose and arabinose. In the batch process, about half of the arabinose was converted, whereas almost all arabinose was converted in the fed-batch case (Figure 1). The con- 


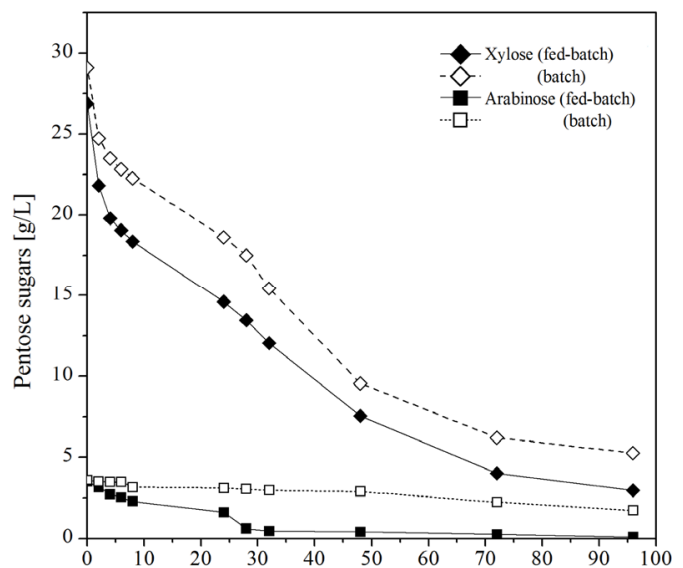

(a)

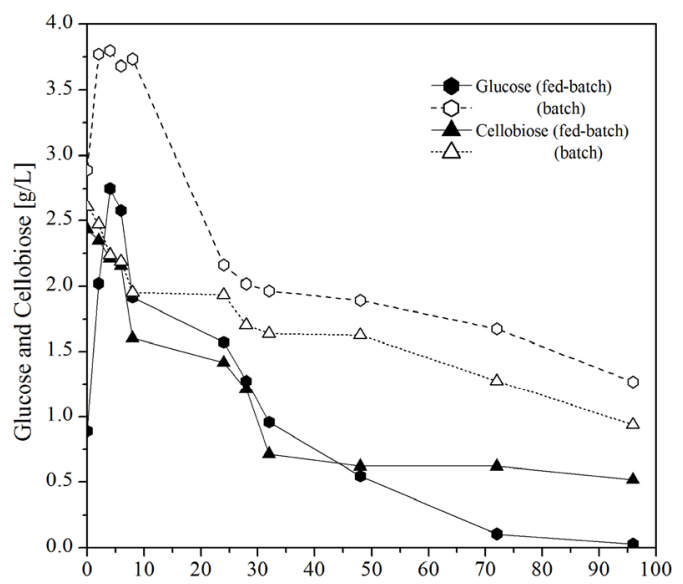

(b)

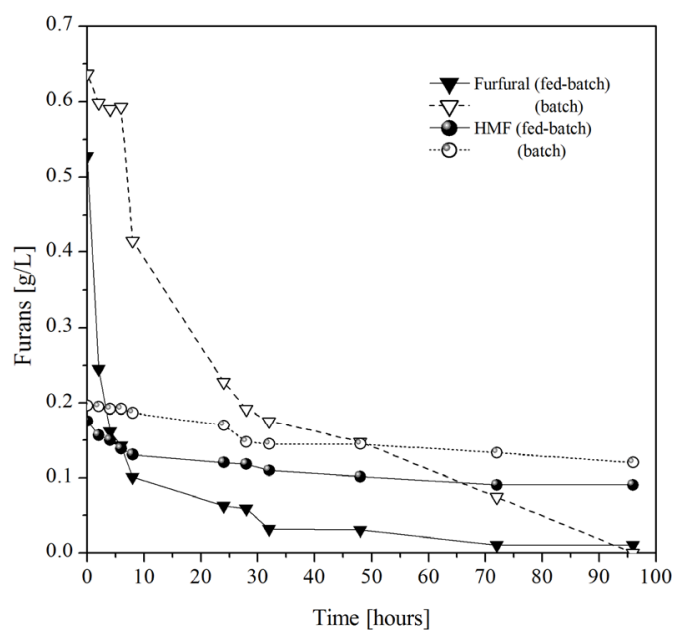

(c)

Figure 1. Concentrations measured in simultaneous saccharification and co-fermentation (SSCF) of pretreated Paja Brava using $P$. stipitis CBS6054. Batch fermentations are shown by dashed lines and open symbols and fed-batch fermentation are shown by continuous lines and filled symbols. (a) Concentration of xylose (diamonds) and arabinose (squares); (b) Concentration of glucose (circles) and cellobiose (triangles); (c) Concentration of furfural (diamonds) and 5-hydroxymethyl furfural (HMF, triangles).

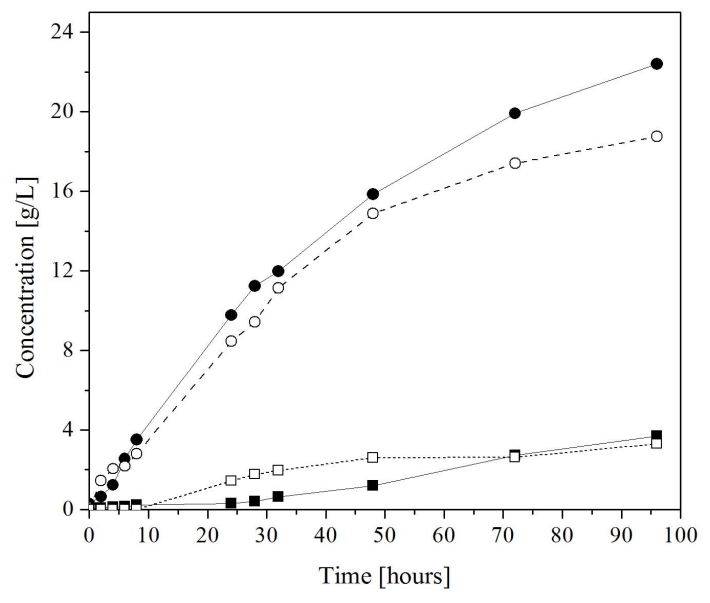

Figure 2. Concentrations of ethanol (circles) and xylitol (squares) measured during batch (dashed line, open symbols) and fed-batch (continuous line, unfilled symbols) simultaneous saccharification and co-fermentation (SSCF) using P. stipitis CBS6054.

version of cellobiose also increased in the fed-batch process, although to a lesser extent. The simultaneous assimilation of sugars suggest that the xylose-metabolizing enzymes, xylose reductase (XR) and xylitol dehydrogenase $(\mathrm{XDH})$, were not repressed by cellobiose and arabinose, which is consistent with the report by Bicho et al. [33] on induction of these enzymes in $P$. stipitis in mixed sugar solutions.

\section{Conclusion}

The current study has shown that steam pretreated Paja Brava can be converted in a fed-batch SSF process up to $10 \%$ WIS with an ethanol yield of $0.27 \mathrm{~g} / \mathrm{g}$ using the natural xylose-fermenting yeast $P$. stipitis. The conversion of xylose was strongly increased in comparison to fermentation of the xylose rich pretreatment liquid alone. Fed-batch operation in the SSF further increased the conversion of xylose, and arabinose. Further improvementsin particular with respect to aeration rates - are necessary to make the $P$. stipitis fermentation competitive with processes using recombinant $S$. cerevisiae.

\section{Acknowledgements}

This work was funded by the Swedish International Development Cooperation Agency (SIDA).

\section{REFERENCES}

[1] H. Alzérreca, "Producción de los Pastizales de la Zonaandina de Bolivia," Red de PastizalesAndinos (REPAAN) y el InstitutoBoliviano de TecnologíaAgropecuaria (IBTA), La Paz, Bolivia, 1992.

[2] K. Olofsson, A. Rudolf and G. Lidén, "Designing Simultaneous Saccharification and Fermentation for Improved 
Xylose Conversion by a Recombinant Strain of Saccharomyces cerevisiae," Journal of Biotechnology, Vol. 134, No. 1, 2008, pp. 112-120. doi:10.1016/j.jbiotec.2008.01.004

[3] C. Carrasco, H. M. Baudel, J. Sendelius, T. Modig, C. Roslander, M. Galbe, B. Hahn-Hägerdal, G. Zacchi and G. Lidén, " $\mathrm{SO}_{2}$-Catalyzed Steam Pretreatment and Fermentation of Enzymatically Hydrolyzed Sugarcane Bagasse," Enzyme and Microbial Technology, Vol. 46, No. 2, 2010, pp. 64-73. doi:10.1016/j.enzmictec.2009.10.016

[4] B. E. Dale and S. Kim, "Biorefineries-Industrial Processes and Product," Wiley-VCH, Weinheim, 2006, pp. 41-66.

[5] K. Olofsson, M. Bertilsson and G. Lidén, "A Short Review on SSF-An Interesting Process Option for Ethanol Production from Lignocellulosic Feedstocks," Biotechnology for Biofuels, Vol. 1, No. 7, 2008, pp. 1-14. doi:10.1186/1754-6834-1-7

[6] J. H. Van Vleet and T. W. Jeffries, "Yeast Metabolic Engineering for Hemicellulosic Ethanol Production," Current Opinions in Biotechnology, Vol. 20, No. 3, 2009, pp. 300-306. doi:10.1016/i.copbio.2009.06.001

[7] C. Carrasco, H. M. Baudel, M. Peñarrieta, C. Solano, L. Tejeda, C. Roslander, M. Galbe and G. Lidén, "Steam Pretreatment and Fermentation of the Straw Material 'Paja Brava' Using Simultaneous Saccharification and Co-Fermentation," Journal of Bioscience and Bioengineering, Vol. 111, No. 2, 2011, pp. 167-174.

doi:10.1016/j.jbiosc.2010.10.009

[8] A. Asghari, R. J. Bothast, J. B. Doran and L. O. Ingram, "Ethanol Production from Hemicellulose Hydrolysates of Agricultural Residues Using Genetically engineered Escherichia coli Strain KO11," Journal of Industrial Microbiology, Vol. 16, No. 1, 1996, pp. 42-47. doi:10.1007/BF01569920

[9] M. Zhang, C. Eddy, K. Deanda, M. Finkelstein and S. Picataggio, "Metabolic Engineering of a Pentose Metabolism Pathway in Ethanologenic Zymomonas mobilis," Science, Vol. 267, No. 5195, 1995, pp. 240-243. doi:10.1126/science.267.5195.240

[10] B. A. Prior, S. G. Kilian and J. C. du Preez, "Fermentation of D-Xylose by the Yeasts Candida shehatae and Pichia stipitis," Process Biochemistry, Vol. 24, No. 1, 1990, pp. 21-32.

[11] K. Skoog and B. Hahn-Hägerdal, "Effect of Oxygenation on Xylose Fermentation by Pichia stipitis," Applied and Environmental Microbiology, Vol. 56, No. 11, 1990, pp. 3389-3394.

[12] F. K. Agbogbo and G. Coward-Kelly, "Cellulosic Ethanol Production Using the Naturally Occurring Xylose-Fermenting Yeast, Pichia stipitis," Biotechnology Letters, Vol. 30, No. 9, 2008, pp. 1515-1524. doi:10.1007/s10529-008-9728-Z

[13] J. N. Nigam, "Development of Xylose-Fermenting Yeast Pichia stipitis for Ethanol Production through Adaptation on Hardwood Hemicellulose acid Prehydrolysate," Journal of Applied Microbiology, Vol. 90, No. 2, 2001, pp. 208-215. doi:10.1046/j.1365-2672.2001.01234.x
[14] A. Almeida, T. Modig, A. Petersson, B. Hahn-Hägerdal, G. Lidén and M. F. Gorwa-Grauslund, "Increased Tolerance and Conversion of Inhibitors in Lignocellulosic Hydrolysates by Saccharomyces cerevisiae," Journal of Chemical Technology and Biotechnology, Vol. 82, No. 4, 2007, pp. 340-349. doi:10.1002/jctb.1676

[15] J. Zhang, D. Chu, J. Huang, Z. Yu, G. Dai and J. Bao, "Simultaneous Saccharification and Ethanol Fermentation at High Corn Stover Solids Loading in a Helical Stirring Bioreactor," Biotechnology and Bioengineering, Vol. 105, No. 4, 2009, pp. 718-728.

[16] E. Palmqvist, B. Hahn-Hägerdal, M. Galbe, M. Larsson, K. Stenberg, Z. Szengyel, Ch. Tengborg and G. Zacchi, "Design and Operation of a Bench-Scale Process Development Unit for the Production of Ethanol from Lignocellulosics," Bioresource Technology, Vol. 58, No. 3, 1996, pp. 171-179. doi:10.1016/S0960-8524(96)00096-X

[17] M. J. Taherzadeh, G. Lidén, L. Gustafsson and C. Niklasson, "The Effects of Pantothenate Deficiency and Acetate Addition on Anaerobic Batch Fermentation of Glucose by Saccharomyces cerevisiae," Applied Biochemistry and Biotechnology, Vol. 46, No. 2, 1996, pp. 176-182.

[18] A. Rudolf, H. Baudel, G. Zacchi, B. Hahn-Hägerdal and G. Lidén, "Simultaneous Saccharification and Fermentation of Steam-Pretreated Bagasse Using Saccharomyces cerevisiae TMB3400 and Pichia stipitis CBS6054," Biotechnology and Bioengineering, Vol. 99, No. 4, 2008, pp. 783-790. doi:10.1002/bit.21636

[19] M. J. Taherzadeh, R. Eklund, L. Gustafsson, C. Niklasson and G. Lidén, "Characterization and Fermentation of Dilute-Acid Hydrolyzates from Wood," Industrial and Engineering Chemical Research, Vol. 36, No. 11, 1999, pp. 4659-4665. doi:10.1021/ie9700831

[20] F. Posey, J. Okafor and C. Roberson, "Determination of Insoluble Solids of Pretreated Biomass Material," National Renewable Energy Laboratory NREL, Biomass Program, Laboratory Analytical Procedure LAP-018, Golden, Co., 1998.

[21] A. Sluiter, B. Hames, R. Ruiz, C. Scarlata, J. Sluiter and D. Templeton, "Determination of Sugars, By-Products, and Degradation Products in Liquid Fraction Process Samples," National Renewable Energy Laboratory NREL, Biomass Program, Golden, Co., 1995.

[22] A. Sluiter, B. Hames, R. Ruiz, C. Scarlata, J. Sluiter, D. Templeton and D. Croker, "Determination of Structural Carbohydrates and Lignin in Biomass," National Renewable Energy Laboratory NREL, Biomass Program, Golden, Co., 2008.

[23] M. Wayman and S. R. Parekh, " $\mathrm{SO}_{2}$ Prehydrolysis for High Yield Ethanol Production from Biomass," Applied Biochemistry and Biotechnology, Vol. 17, No. 1-3, 1988, pp. 33-43. doi:10.1007/BF02779144

[24] N. Q. Meinander, I. Boels and B. Hahn-Hägerdal, "Fermentation of Xylose/Glucose Mixtures by Metabolically Engineered Saccharomyces cerevisiae Strains Expressing XYL1 and XYL2 from Pichia stipitis with and without Overexpression of TAL1," Bioresource Technology, Vol. 68 , No. 1,1999 , pp. 79-87. doi:10.1016/S0960-8524(98)00085-6 
[25] M. Taniguchi, T. Tohma, T. Itaya and M. Fujii, "Ethanol Production from a Mixture of Glucose and Xylose by Co-Culture of Pichia stipitis and a Respiratory-Deficient Mutant of Saccharomyces cerevisiae," Journal of Fermentation and Bioengineering, Vol. 83, No. 4, 1997, pp. 364-370. doi:10.1016/S0922-338X(97)80143-2

[26] S. G. Kilian and N. van Uden, "Transport of Xylose and Glucose in the Xylose-Fermenting Yeast Pichia stipitis," Applied Microbiology and Biotechnology, Vol. 27, No. 5-6, 1988, pp. 545-548.

[27] A. L. Does and L. F. Bisson, "Characterization of Xylose Uptake in the Yeasts Pichia heedii and Pichia stipitis," Applied and Environmental Microbiology, Vol. 55, No. 1, 1989, pp. 159-164.

[28] C. J. Panchal, L. Bast, I. Rusell and G. G. Stewart, "Repression of Xylose Utilization by Glucose in Xylose-Fermenting Yeasts," Canadian Journal of Microbiology, Vol. 34, 1998, pp. 1316-1320. doi:10.1139/m88-230

[29] F. K. Agbogbo, G. Coward-Kelly, M. Torry-Smith and K. S. Wenger, "Fermentation of Glucose/Xylose Mixtures Using Pichia stipitis," Process Biochemistry, Vol. 41, No. 11, 2006, pp. 2333-2336. doi:10.1016/j.procbio.2006.05.004

[30] K. Olofsson, M. Wiman and G. Lidén, "Controlled Feeding of Cellulases Improves Conversion of Xylose in Simultaneous Saccharification and Co-Fermentation for Bioethanol Production," Journal of Biotechnology, Vol. 145, No. 2, 2010, pp. 168-175.

doi:10.1016/j.jbiotec.2009.11.001

[31] J. R. M. Almeida, T. Modig, A. Röder, G. Lidén and M. F. Gorwa-Grauslund, "Pichia stipitis Xylose Reductase Helps Detoxifying Lignocellulosic Hydrolysate by Reducing 5Hydroxymethyl-Furfural (HMF)," Biotechnology for Biofuels, Vol. 1, 2008, p. 12. doi:10.1186/1754-6834-1-12

[32] X. Y. Jing, X. Zhang and J. Bao, "Inhibition Performance of Lignocellulose Degradation Products on Industrial Cellulase Enzymes during Cellulose Hydrolysis," Applied Biochemistry and Biotechnology, Vol. 159, No. 3, 2009, pp. 696-707. doi:10.1007/s12010-009-8525-Z

[33] P. A. Bicho, P. L. Runnals, J. D. Cunningham and H. Lee, "Induction of Xylose Reductase and Xylitol Dehydrogenase Activities in Pachysolentannophilus and Pichia stipitis on Mixed Sugars," Applied and Environmental Microbiology, Vol. 54, No. 1, 1988, pp. 50-54. 